This is a self-archived version of an original article. This version may differ from the original in pagination and typographic details.

Author(s): Tynkkynen, Katja; Kotiaho, Janne Sakari; Svensson, Erik I.

Title: Interspecific interactions and premating reproductive isolation

Year: 2008

Version: Published version

Copyright: (c) Oxford University Press, 2008.

Rights: In Copyright

Rights url: http://rightsstatements.org/page//nC/1.0/?language=en

Please cite the original version:

Tynkkynen, K., Kotiaho, J. S., \& Svensson, E. I. (2008). Interspecific interactions and premating reproductive isolation. In A. Gordoba-Aguilar (Ed.), Dragonflies: Model Organisms for Ecological and Evolutionary Research (pp. 139-152). 


\title{
Interspecific interactions and premating reproductive isolation
}

\author{
Katja Tynkkynen, Janne S. Kotiaho, and Erik I. Svensson
}

\section{Overview}

Interspecific interactions have several evolutionary consequences: for example, two species may compete, hybridize, or behave aggressively towards each other, or there may be predator-prey interactions. One consequence of these interactions is the evolution of premating reproductive isolation between the two species. The most obvious interspecific interaction, which has an effect on reproductive isolation, is the avoidance of hybridization, or, in other words, the reinforcement process. The theory of reinforcement states that when hybridization is maladaptive, selection pressure causes a divergence in female mate preference and/or in male secondary sexual characters. It is often assumed that, ultimately, females are responsible for hybridization because they are the choosier sex and their co-operation is needed for successful copulations. Despite this view, it is possible that males, rather than females, are responsible for hybridization, especially in species in which males can force copulations. In addition to the avoidance of maladaptive hybridization, other interspecific interactions, such as aggression or predation, may also have an effect on premating reproductive isolation. For example, if interspecific aggression is directed towards males with the most exaggerated sexual characters because of the similarity of these characters between the two species, natural selection for sexual character divergence may arise. Just like the reinforcement process, this process may lead to a strengthening of premating reproductive isolation. In this chapter, we will review the effect of interspecific interactions on premating reproductive isolation. As examples we will mostly use the studies conducted on Calopteryx damselflies.

\subsection{Introduction}

In nature, there are several kinds of interaction between species. Species can be involved in predator-prey interactions (including parasites; Zuk and Kolluru 1998; Kotiaho 2001; Svensson and Friberg 2007), they may compete or defend territories against each other (e.g. Nomakuchi and Higashi 1996; Genner et al. 1999; Adams 2004; Tynkkynen et al. 2006), and two species can hybridize (see Mallet 2005). Interactions between species can have evolutionary consequences, influencing reproductive isolation (Box 11.1) and speciation events. For example, competition over resources can cause divergent selection on ecological or behavioural traits, strengthening premating isolation between the two incipient species (see Coyne and Orr 2004 for a review of speciation).

Although there are several factors which may affect reproductive isolation, we will here concentrate on two questions. First, how can interspecific interactions, especially hybridization, aggression, and predation, affect premating reproductive isolation? Second, is reproductive isolation a direct target of selection or does it evolve as a correlated response to selection on other traits? We will mainly use Calopteryx damselflies as a model species, which have been under intensive study concerning our study questions. 


\section{Box 11.1 Reproductive isolation}

Reproductive isolation can arise from several reproductive barriers, which may work before or after mating. Pre-mating barriers include factors that prevent the occurrence of mating, whereas post-mating reproductive barriers include factors that, after mating, prevent the formation of offspring, or that cause the hybrid offspring to be unviable or sterile (Coyne and Orr 2004).

In this chapter, we concentrate on pre-mating reproductive isolation. Pre-mating reproductive isolation can be classified as caused by several factors (see Coyne and Orr 2004 for more detailed description). First, there may be sexual isolation (also called behavioural isolation), in which reproductive isolation is based on behavioural differences between two species, or mate-recognition ability of individuals (for an example case, see Box 11.2). Second is ecological isolation, which means that gene flow between species is impeded because of a divergence in habitat or timing of reproduction. Finally, mechanical isolation occurs when reproductive structures are incompatible, thus preventing normal copulation (Coyne and Orr 2004).

\subsection{Causes and evolutionary consequences of hybridization in animals}

Hybridization means crossing of genetically distinguishable groups or taxa, leading to the production of viable hybrids (sensu Mallet 2005). Hybridization is a surprisingly prevalent phenomenon in nature: at least $25 \%$ of plant species and $10 \%$ of animal species hybridize (Mallet 2005). In animals, hybridization is mostly observed in conspicuous and intensively studied taxa such as birds (Grant and Grant 1992), mammals (see Coyne and Orr 2004), Drosophila (Coyne and Orr 1989; Mallet 2005), and butterflies (Mallet 2005). In odonates, some suspected and verified hybrids have been observed (e.g. Asahina 1974; Bick and Bick 1981; Corbet 1999; Monetti et al. 2002; Sánchez-Guillén et al. 2005). However, odonate hybrids may be more common than reported, since precopulative tandems and matings between heterospecifics are commonly observed in nature (Corbet 1999).

\subsubsection{Why do animals hybridize?}

A pair of species can hybridize only if they occur in sympatry (at the same place), and if they have incomplete pre- and postmating isolation barriers. In animals, the ultimate causes of hybridization can roughly be divided into two groups: either there is incomplete mate-recognition ability (e.g. Sætre et al. 1997a; Randler 2002) or hybridization is the result of adaptive decision-making (Nuechterlein and Buitron 1998; Wirtz 1999; Veen et al. 2001).

Hybridization can be caused by incomplete materecognition ability, if, for example, behavioural isolation between the two species is incomplete. Such is the case for instance, when the two species have occurred in allopatry (at separate places), and then subsequently become sympatric. Here, the materecognition ability that evolved in allopatry may be poorly adapted to discriminating heterospecifics. It is also possible that two or more closely related species occur in sympatry without hybridization, but after some environmental change, they start to hybridize (Rhymer and Simberloff 1996; Seehausen et al. 1997a; Lamont et al. 2003; Box 11.2).

Hybridization is not always maladaptive. For example, when an individual is unable to find a conspecific mate, it may do better by breeding with a heterospecific than not at all. This adaptive explanation for hybridization requires that the hybridizing individual gains some fitness return, meaning that hybrids can have reduced, but non-zero fitness (Grant and Grant 1992; Nuechterlein and Buitron 1998; Sætre et al. 1999; Wirtz 1999; Veen et al. 2001; Randler 2002). However, the two origins for hybridization, incomplete mate-recognition ability and adaptive decision-making, are not mutually exclusive, since both may occur at the same time within a sympatric population (Sætre et al. 1997a; Veen et al. 2001). 


\section{Box 11.2 An example of the relaxation of pre-mating reproductive isolation}

In Lake Victoria are at least 500 endemic haplochromine cichlid fish species (Seehausen et al. 1997b). In these cichlid species, male coloration is an important factor in sexual selection, and works as a pre-mating isolating barrier between species (Seehausen et al. 1997a; Seehausen and van Alphen 1998). Females of the cichlid species are able to recognize conspecific males based on their coloration in clear water conditions. However, recent anthropogenic disturbance has increased the water turbidity and the coloration of the males is not easy for the females to observe. This has caused matings between heterospecifics that result in viable and fertile hybrids (Seehausen et al. 1997a). Thus, the relaxation of pre-mating reproductive isolation due to anthropogenic environmental change has resulted in formation of hybrid swarms, and may have lead to species extinctions through introgression (Seehausen et al. 1997a).

\subsubsection{Consequences of hybridization}

Hybridization leads to different outcomes depending on the viability and fertility of the hybrid individuals. If hybrid fitness is not reduced, or if it is even higher than that of parents (a phenomenon known as heterosis), the mechanisms to avoid hybridization are not strong or are missing, and the gene pool of the two species may eventually fuse (see, for example, Coyne and Orr 2004; Taylor et al. 2006). In such a case, if one species is less abundant than the other, the fusion of the gene pools may lead to extinction of the less-abundant species (or the sympatric population) (e.g. Liou and Price 1994; Rhymer and Simberloff 1996; Levin 2004). In the example of the Lake Victoria cichlid fishes (Box 11.2), relaxation of premating reproductive isolation had resulted in extinctions though introgression (Seehausen et al. 1997a).

When species hybridize there is often a catastrophic reduction in fitness, and thus selection to avoid interspecific matings is likely to be very strong. As a consequence, the mate preferences and the sexual characters of a pair of potentially hybridizing species may diverge. This process is referred to as reinforcement because it should reinforce premating reproductive isolation of the species (e.g. Dobzhansky 1951; Howard 1993; Sætre et al. 1997a; Rundle and Schluter 1998; Noor 1999; Higgie et al. 2000). As a result of reinforcement, the probability of copulation between heterospecifics, and thus the occurrence of hybrids in the wild, is reduced. The divergence of reproductively isolating traits between allopatric and sympatric populations of two species is referred to as reproductive character displacement (sensu Howard 1993; see Butlin 1987 for a different definition of the concepts). The pattern may also be observed across sympatric populations, in which the divergence of isolation traits depends on the relative abundance of the sympatric species (Howard 1993; Noor 1999; Tynkkynen et al. 2004). It should also be taken into account, that in addition to hybridization, matings between heterospecifics without production of hybrids may cause selection for reproductive isolation, if mating or courtship itself has a negative effect on fitness (see Chapman et al. 1998; Kotiaho et al. 1998; Kotiaho 2001).

When premating isolation has been reinforced such that matings between heterospecifics are not prevalent, the selection to further enhance the premating isolation may relax. It is possible, however, that sexual selection develops along with the reinforcement process, and that its role increases when reinforcement proceeds (Liou and Price 1994; Coyne and Orr 2004; Mallet 2005). When sexual traits or female mate preferences are shaped by reinforcement (i.e. by natural selection), a genetic correlation will be formed between male sex traits and female mate preference (Lande 1981; see also Liou and Price 1994; Coyne and Orr 2004). Similar patterns to reinforcement may also be caused by forces other than avoidance of maladaptive hybridization. For example, ecological factors and the associated selection pressures may cause premating reproductive 
isolation, which arises as a byproduct to divergent natural selection on different populations (e.g. Noor 1999; Coyne and Orr 2004; Mullen and Andrés 2007; see also Servedio 2001). One such ecological factor is interspecific aggression; an example of which is described later in this chapter.

\subsubsection{Male coercion behaviour: can it lead to hybridization in odonates?}

In general, females are thought to be choosy and it seems that female cooperation is frequently needed for a successful copulation. Therefore, it has been proposed that it is the females who are mainly responsible for hybridization (Sætre et al. 1997b; Wirtz 1999; Randler 2002). However, in some cases, males can coerce females to copulation, and thus male choosiness should not be neglected (e.g. Cordero 1999; Cordero and Andrés 2002). If females are indeed the choosier sex, it may be too costly for males to evolve to be choosy, since mating opportunies with conspecific females may also be missed (Parker 1983; Sætre et al. 1997b; Parker and Partridge 1998; Wirtz 1999). Nevertheless, it is likely that males will also be selected to display some discrimination of conspecifics, especially if the costs of reproduction activities are high (Wirtz 1999).

In some species of odonates, males are able to grasp a female and form the precopulatory tandem, and the females may have little option but to mate (Oppenheimer and Waage 1987; Cordero and Andrés 2002). This is the case in Calopteryx damselflies: when the anal appendages of the male grab the female neck to produce the tandem position, the pair usually proceeds with copulation (Oppenheimer and Waage 1987). Moreover, in most odonates it is unclear whether female mate choice even occurs (see Fincke 1997; Fincke et al. 1997; but see Córdoba-Aguilar 2006). The role of female mate choice seems to be more clear in calopterygid damselflies, in which males have conspicuously pigmented wings, and in which males court females by performing a flight display (Fincke et al. 1997; Siva-Jothy 1999; Córdoba-Aguilar 2002). However, since even in these species males can force females to mate (Cordero 1999; Cordero and Andrés 2002), it is thus still unclear who is, in fact, in control of the onset of mating.
Interestingly, in his classical studies, Waage $(1975,1979)$ suggested that character displacement observed in wing pigmentation of Calopteryx maculata and Calopteryx aquabilis is caused by avoidance of maladaptive hybridization by males rather than females. Although hybrids were not found, Waage (1975) observed copulations between heterospecifics followed by oviposition. Males of C. maculata had better mate-discrimination ability in sympatric populations than in allopatric ones, indicating occurrence of reinforcement. The selection for better mate discrimination may also have caused reproductive character displacement on female wing transparency; that is, on the trait in which males base their species recognition (Waage 1975, 1979). It is particularly interesting that in this case reproductive character displacement was observed in female characteristics and in male mate discrimination (Waage 1975, 1979), because in most other studies of reproductive character displacement it is the male secondary sexual characters or female mate-discrimination ability that has been investigated (e.g. Howard 1993; Sætre et al. 1997a; Rundle and Schluter 1998; Noor 1999; Higgie et al. 2000). It should be noted, however, that the suggestion of reinforcement made by Waage (1975) was challenged recently by the suggestion that reproductive character displacement may have arisen from selection caused by interference between mate-recognition signals rather than reinforcement (Mullen and Andrés 2007).

The role of females and males in reproductive isolation has been studied in detail in Calopteryx splendens and Calopteryx virgo. Hybrids between these two species occur in nature in low prevalence (less than $1 \%$ of adult individuals), but matings between heterospecifics are frequent (Svensson et al. 2007; K. Tynkkynen, J.S. Kotiaho, M. Luojumäki, and J.Suhonen, unpublished results). The discrepancy between number of observed matings and hybrids, and the pronounced genetic distance between the two species (Misof et al. 2000; Weekers et al. 2001), suggests that hybridization is likely to be maladaptive.

Females of these species mate assortatively and use male wing coloration as a visual cue in species recognition (Svensson et al. 2007). C. splendens males have melanized wing spots in their wings covering 

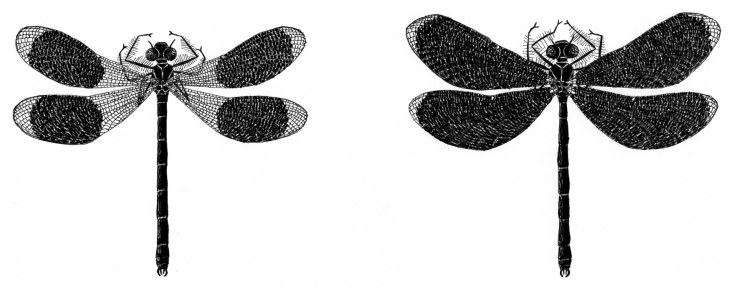

$1 \mathrm{~cm}$

Figure 11.1 Males of Calopteryx splendens (left) and Calopteryx virgo (right). Artwork provided kindly by the artist Kaisa J. Raatikainen.

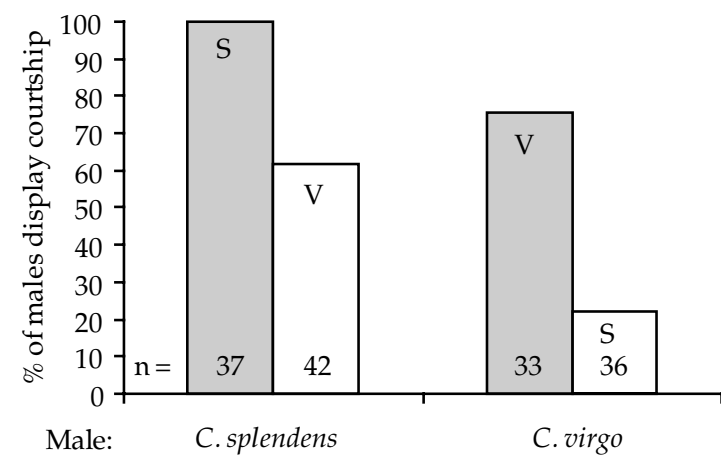

Figure 11.2 Percentage of males displaying courtship to conspecific (grey bars) or heterospecific (white bars) females. S indicates C. splendens and V means C. virgo females (Tynkkynen et al., 2008). Reproduced with permission from Elsevier.

about $30-70 \%$ of wing area, and C. virgo have almost completely pigmented wings (Figure 11.1). As the extent of the wing pigmentation of $C$. splendens males was manipulated to resemble that of $C$. virgo, C. virgo females became more willing to copulate with $C$. splendens males, and at the same time the willingness of $C$. splendens females decreased (Svensson et al. 2007). Thus, there is strong sexual premating reproductive isolation between the two species (Svensson et al. 2007).

There is also a difference between C. splendens and $C$. virgo males in courting activity towards conspecific and heterospecific females (Tynkkynen et al. 2008; Figure 11.2). In central Finland, it was found that when heterospecific females were presented to territorial males of both species in field experiments, C. splendens courted as many as $62 \%$ of the females, whereas C. virgo courted only $22 \%$ of the females (Figure 11.2). This suggests, that in contrast to females, among which the sexual premating reproductive isolation was strong (Svensson et al. 2007), the premating isolation in C. splendens males was incomplete. The same asymmetrical discrimination between males of the two species was verified independently in a study in southern Sweden, where it was found that $C$. splendens males copulate with heterospecific females in the field more often than do C. virgo males (Svensson et al. 2007). In contrast, $C$. virgo males were apparently more discriminatory towards heterospecific members of the opposite sex than females in both species and C. splendens males (Svensson et al. 2007). Thus, in the genus Calopteryx, a consideration of male mating behaviours and male mate choice, not just female mate choice, is crucial to understand the causes of hybridization. It is possible that eagerly courting $C$. splendens males are able to force $C$. virgo females to copulate (see Cordero 1999; Cordero and Andrés 2002), and C. virgo females yield to mating since it may be costly for them to resist persistent harassment from C. splendens males. The elevated species-recognition ability and choosiness of C. virgo males (Svensson et al. 2007; Tynkkynen et al. 2008) may be due to the sex- and speciesspecific costs of matings: $C$. virgo males have an elevated predation risk from birds, presumably because of their more conspicuous, entirely dark wings (Svensson and Friberg 2007).

\subsection{Interspecific aggression}

\subsubsection{Causes for interspecific aggression}

There are at least two causes of interspecific aggression: it can result from interspecific interference competition over resources or from mistaken species recognition. The first is probably more common, as documented by published studies (e.g. Nomakuchi and Higashi 1996; Genner et al. 1999; Adams 2004).

Aggressive behaviour related to territorial defence can mistakenly be directed towards heterospecific individuals due to their phenotypic similarity (Murray 1981; Nishikawa 1987; Alatalo et al. 1994; Tynkkynen et al. 2004). For example, interspecific 
(a)

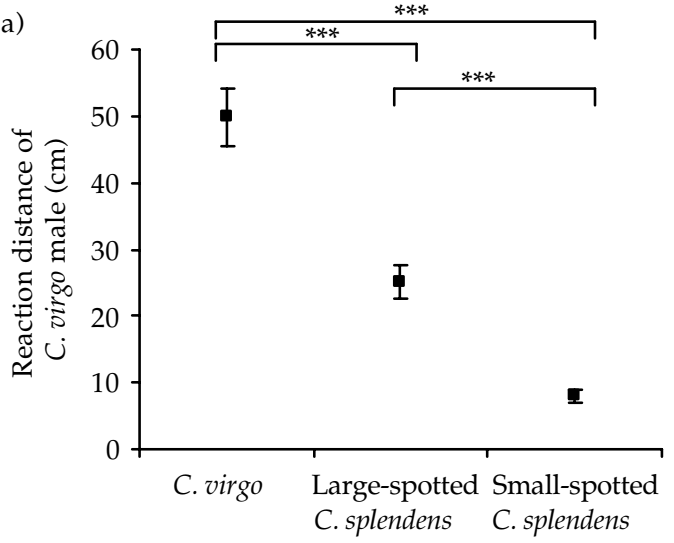

(b)

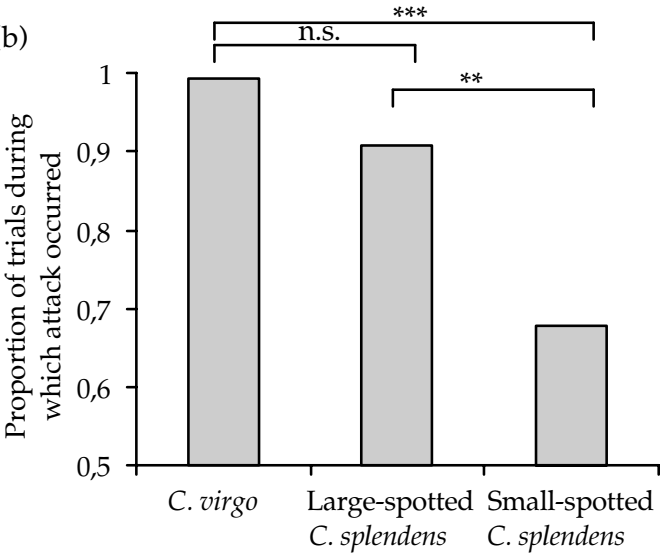

(d)

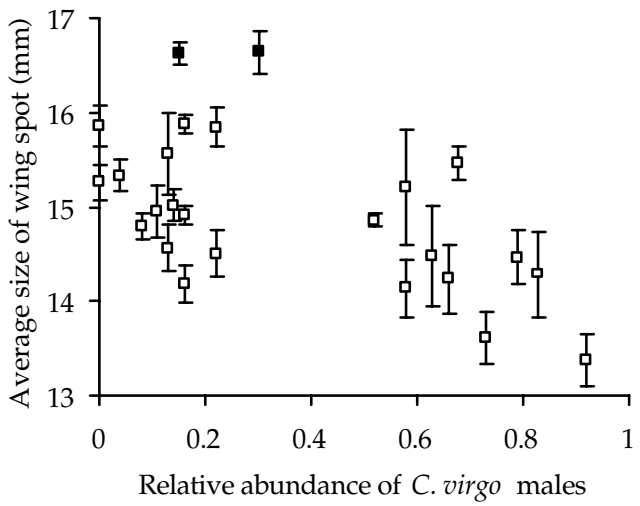

Figure 11.3 Interspecific aggression and character displacement in C. splendens and C. virgo males. (a, b) Results from the experiment in which aggressiveness of territorial C. virgo males was determined towards C. virgo, and C. splendens males with large and small wing spots. Reaction distance (a) and aggressiveness of reactions (b) were observed. Aggressiveness of reactions is indicated by proportions of trials in which attack occurred (Tynkkynen et al. 2004). NS, not significant; ${ }^{*} P<0.01,{ }^{*} * P<0.001$. (c) Standardized selection differentials (measures of directional selection) on wing-spot size of $C$. splendens males in relation to relative abundance of $C$. virgo males. Filled circles indicate natural populations (controls), and open circles populations in which the relative abundance of $C$. virgo is reduced. There is significant interaction between the control and treatment (ANCOVA, $F_{1,3}=17.05, P=0.026$; Tynkkynen et al. 2005). For individual selection differentials, ${ }^{*} P<0.05$. (d) Character displacement in wing-spot size of $C$. splendens males. The spot size decreases as relative abundance of $C$. virgo males (number of $C$. virgo males divided by the total number of both species) increases. The two populations indicated by filled circles are geographically distant, eastern populations (Tynkkynen et al. 2004). Reproduced with permission from Blackwell Publishing.

aggression occurs between males of $C$. virgo and C. splendens, and the aggression seems to be at least partially based on mistaken species recognition (although there may also be a component of interference competition over territories or oviposition sites) (Tynkkynen et al. 2004, 2006). C. virgo males react from greater distance to large-spotted C. splendens males, but they are also more aggressive towards large-spotted than small-spotted C. splendens
(Figures 11.1 and 11.3a and b). Thus, it seems that, at least partially, interspecific aggression between C. virgo and C. splendens is based on mistaken species recognition. This is because if the behaviour was due to interference competition, $C$. virgo males should be equally aggressive towards large-spotted and small-spotted C. splendens males, whereas reaction distance could still vary, if the large-spotted C. splendens males are more detectable. 


\subsubsection{Consequences of interspecific aggression on premating reproductive isolation}

Interspecific aggression may have an effect on premating reproductive isolation of closely related sympatric species at least in two ways. First, interspecific interference competition may cause ecological reproductive barriers to emerge. In other words, there may be shifts in habitat use or behavioural adaptations to avoid contacts with the heterospecific individuals. Such avoidance may lead into strengthening premating reproductive isolation (see Coyne and Orr 2004; Adams 2004). Second, interspecific aggression due to mistaken species recognition may have an effect on male sexual characters, which in turn may affect premating reproductive isolation through female mate choice or through interspecific male-male competition (e.g. Tynkkynen et al. 2004,2005 ). Regardless of the origin of the aggression, interspecific aggression can reduce the fitness of the target. For example, interspecific aggression may force individuals of subdominant species to less preferred habitats or territories (Alatalo et al. 1994; Nomakuchi and Higashi 1996; Martin and Martin 2001; Melville 2002), it may reduce attractiveness of males to females when males are the targets of excessive interspecific harassment, or it may reduce the survival of individuals through injuries or depletion of energy reserves (e.g. Eccard and Ylönen 2002; Tynkkynen et al. 2005; Figure 11.3c). In addition, energetically demanding fighting with heterospecifics may reduce territory-holding potential and thus decrease territorial life span, which in turn can reduce reproductive success (Tynkkynen et al. 2006).

As an example, interspecific aggression from C. virgo towards large-spotted C. splendens males could have caused character displacement to the wing spot of $C$. splendens males such that wing-spot size decreases with increasing relative abundance of C. virgo males (Tynkkynen et al. 2004; Figure 11.3d). If the similarity between the males of the two species decreases, it may facilitate female mate recognition. In addition, it may cause a genetic correlation between a male sexual character and female mate preference (see Lande 1981). A genetic correlation may arise if males with a certain wing-spot size avoid interspecific aggression, but have sufficiently large spots to appeal to females, giving these males an advantage in both natural and sexual selection. If this process occurs, it may enhance premating reproductive isolation between the species. Thus, it seems likely that interspecific aggression has a role in creating premating reproductive isolation between the two Calopteryx species (Mullen and Andrés 2007; Tynkkynen et al. 2008).

\subsection{A role for predation in the evolution of premating isolation}

An influential review on laboratory selection experiments in Drosophila concluded that reproductive isolation between populations may often evolve as a correlated response to divergent natural selection between different environments (Rice and Hostert 1993). If two populations are inhabiting different environments and have different ecologies, they will become reproductively isolated from each other, given sufficient time, even if some gene flow connects the populations (Rice and Hostert 1993). This is the so-called byproduct model of speciation, which has been advocated by many workers since Ernst Mayr and in which there is no particular need to invoke any direct or indirect fitness benefits to males or for females to choose their own conspecifics as mates (Coyne and Orr 2004). There is very strong empirical support for this byproduct model of speciation, which is valid for both allopatric and sympatric scenarios (Endler 1977; Hendry et al. 2000; Hendry 2001; Svensson et al. 2006).

Given the strong evidence for the byproduct model of speciation, it follows that investigators should focus on ecologically important traits between species or incipient species, and estimate the form and direction of natural or sexual selection on the same traits. Interspecific differences in wing coloration in Calopteryx damselflies are particularly interesting in this context since they function as a species-recognition mechanisms in both males and in females (see above). If natural or sexual selection on such wing colour differs between populations, divergent selection could cause sexual isolation and speciation as a correlated response. Interestingly, the extent of wing melanization and darkness of the wing patches 

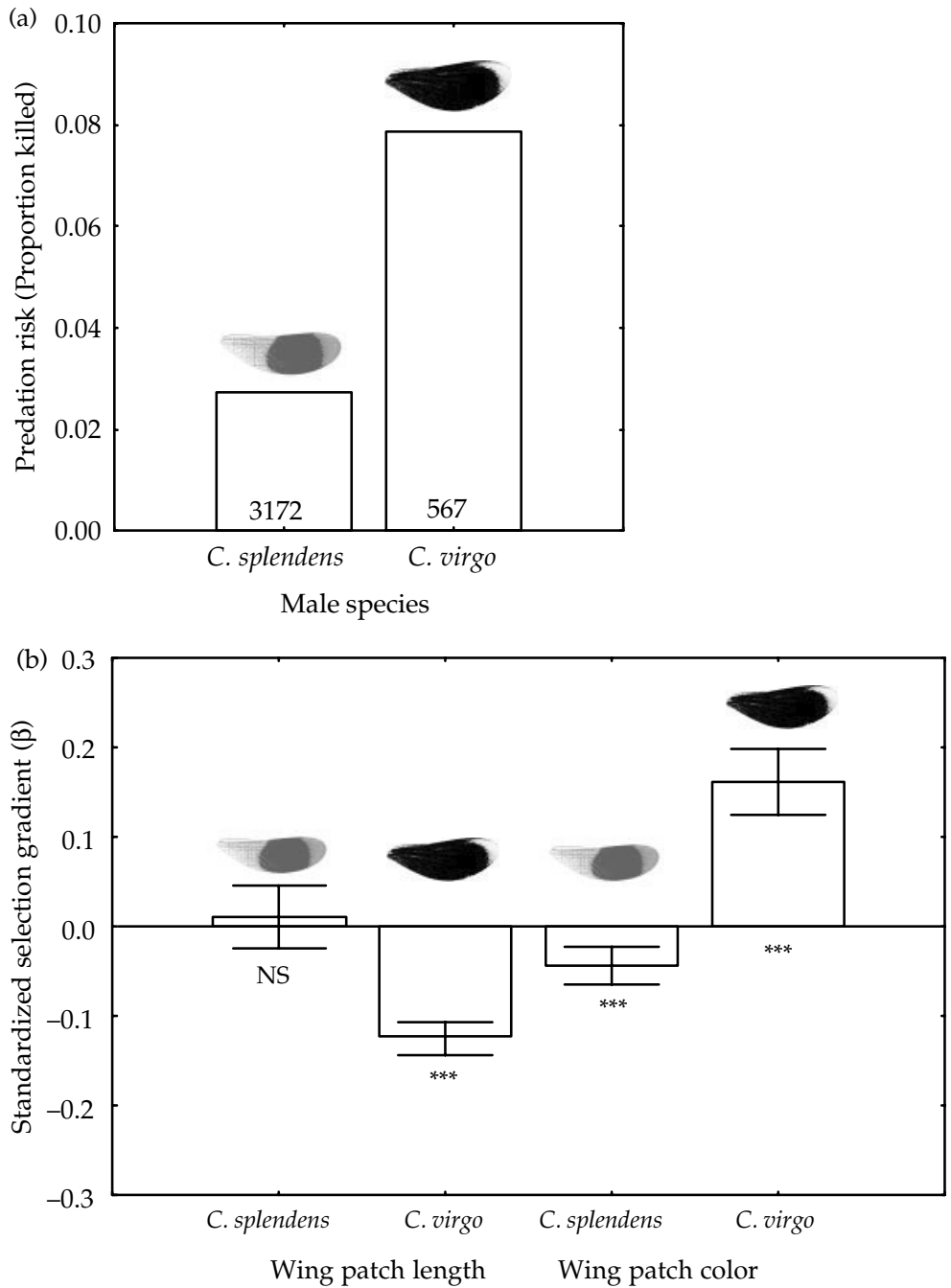

Figure 11.4 (a) Species-specific predation by Motacilla alba on C. splendens and C. virgo males. Male C. virgo suffered a 2.9-times-higher predation risk from wagtails than did male C. splendens and this difference was highly significant $(99.9 \%$ confidence interval, 1.54-4.82; $P<0.001)$. Sample sizes (total no. of live and dead males) for each species are also provided in graph. Wings of the two different species inserted in graph for comparison. Note the almost entirely melanized wings in C. virgo, compared with C. splendens males. (b) Directional selection gradients $(\beta)$ on wing coloration of $C$. splendens and $C$. virgo. Selection gradients on wings were estimated from morphological measurements of predated individuals and these wings were compared with measurements of live males captured at the same time and at the same locality (see Svensson et al. 2007). The selection gradients for all traits differed significantly between species $(P<0.001$, in all cases) Estimated means $\pm 95 \%$ confidence intervals are shown in figure. NS, not significant; ${ }^{* *} P<0.001$. Reproduced with permission from Chicago University Press.

has a strong effect on predation risk by white wagtails (Motacilla alba) at a sympatric locality of C. splendens and C. virgo in southern Sweden (Figure 11.4) (Svensson and Friberg 2007). C. virgo, which has entirely dark wings (Figure 11.1), and is thus presumably more visible to avian predators, had an almost three-times-higher predation risk than sympatric C. splendens males (Figure 11.4a). Moreover, both wing-spot size and the intensity of wing-spot darkness were subject to natural 
selection, although the selection pressures differed between the two species (Figure 11.4b). Predation selected for a reduced extent of wing melanization but darker spots in C. virgo, whereas selection on the smaller wing spot in C. splendens was not as pronounced (Figure 11.4b). Taken together, these data indicate that predator-mediated selection acts on wing melanization and hence such selection could potentially interfere with both the characterdisplacement process between these two species and may indirectly also affect the development of reproductive isolation between populations or species. More generally, the evolution of reproductive isolation between incipient species is thought to be facilitated if the species-recognition characters are subject to direct selection, as in this case, rather than if the species-recognition characters are only 'arbitrary' signalling traits that are only subject to indirect selection (Felsenstein 1981; Dieckmann and Doebeli 1999).

\subsection{Sexual isolation as a result of direct or indirect selection on female mate preferences, or a correlated response to divergent sexual selection?}

Natural selection on the melanized wing spots in the genus Calopteryx could have caused sexual isolation (see Box 11.1) in this genus, irrespective of whether natural selection was caused by male interspecific interactions (Tynkkynen et al. 2004, 2005,2006 ) or by avian predation (Svensson and Friberg 2007). However, studies on sexual isolation should preferably also be performed at lower taxonomic levels than species; that is, between conspecific populations. Such studies are still rare, relative to the numerous laboratory studies on Drosophila (Rice and Hostert 1993; Coyne and Orr 2004). Ideally, such studies should be performed not only between allopatric populations experiencing little or no gene flow, but between parapatric populations with varying degree of gene flow (Hendry et al. 2000; Hendry 2001), combined with simultaneous estimation of natural and/or sexual selection regimes in the different populations (Svensson et al. 2006). Sexual isolation could evolve between such parapatric populations, even in the presence of gene flow, provided that natural and/or sexual selection is strong enough to overcome the homogenizing effects of gene flow (Smith et al. 1997; Hendry et al. 2002; Svensson et al. 2006). Most previous studies in this area have focused on the role of divergent natural selection and the associated effects on the development of reproductive isolation (Nosil et al. 2002, 2003; Nosil 2004). However, divergent sexual selection can also cause sexual isolation as a correlated response, although the empirical evidence for this is much more limited (Lande 1981; McPeek and Brown 2000; Svensson et al. 2006).

Svensson et al. (2004) have studied divergent sexual selection and sexual isolation within conspecific populations of C. splendens in southern Sweden. These populations are connected by varying degrees of gene flow, as revealed by analysis of molecular population divergence using amplifiedfragment length polymorphism (AFLP) markers (Svensson et al. 2004). The average neutral molecular population divergence between 12 populations (pairwise $\mathrm{F}_{\mathrm{st}}$ ) ranges from close to zero to approximately 0.13 (Svensson et al. 2004), implying strong to moderate gene flow and varying degrees of parapatry between these populations. In spite of ongoing gene flow, sexual isolation has apparently evolved since in six out of seven populations, experimental 'immigrant' males presented to local females in the field have lower courtship success than local males (Figure 11.5a). We also confirmed, in a reciprocal transplant experiment between two of our most intensively studied populations experiencing more or less full gene flow $\left(\mathrm{F}_{\mathrm{st}} \approx 0\right)$, that local females to a large extent preferred their own local males, rather than immigrant males (Figure 11.5b). The average courtship success of immigrant males was about 0.85 compared with local males; that is, a selection coefficient of -0.15 against immigrant males (Svensson et al. 2006). The average courtship success of male categories in this study was estimated from the average female responses to tethered males, measured on an 11-degree scale that takes into account all the distinct precopulatory behaviours in Calopteryx (Svensson et al. 2006). Such a strong selection coefficient against immigrant males could be the result of either strong direct selection against females mating with immigrant males; for example, because of physical injury or increased predation risk, a possibility that we consider unlikely. 

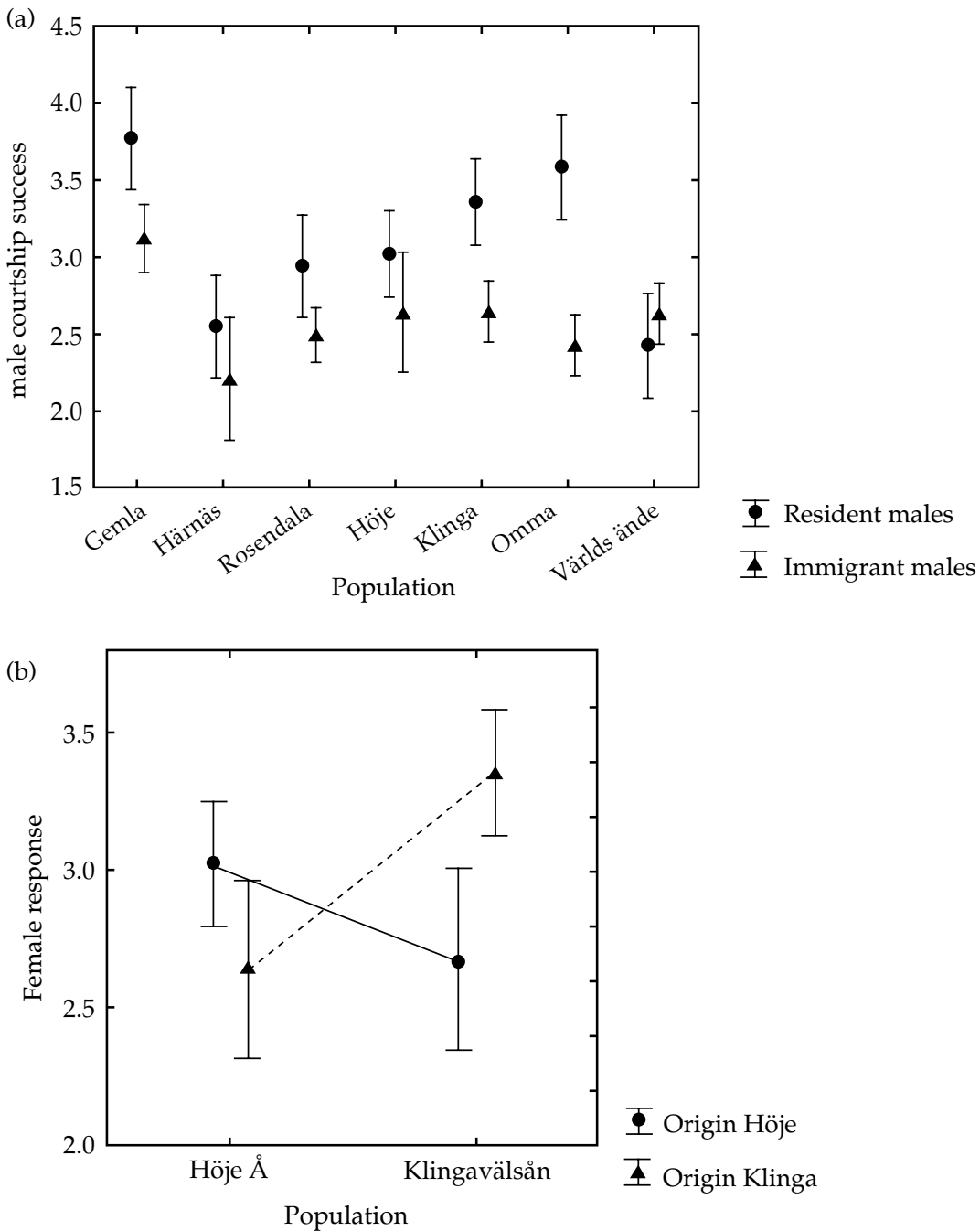

Figure 11.5 (a) Differences (means $\pm 95 \%$ confidence interval) in male courtship success (measured by monitoring female response; $y$ axis) between resident males and experimental 'immigrant' males in seven different populations of $C$. splendens. Female courtship response towards residents and immigrants was quantified on a nominal scale using well-described and distinct precopulatory behaviors (Svensson et al. 2006). Each male was presented to several different females in tethering experiments in the field, and the average female response was used as a measure of male courtship success. (b) A sexually selected fitness trade-off between two damselfly populations differing in morphology and ecology. Resident males have higher courtship success towards females than experimental immigrant males, resulting in a significant phenotype $\times$ origin population interaction (Svensson et al. 2006). Reproduced with permission from Blackwell Publishing.

Another possibly more likely explanation is that sexual isolation has arisen as a correlated response to strong divergent selection between these populations. Sexual selection is clearly divergent between these populations (Svensson et al. 2006), so there is a clear potential for premating isolation to develop as a purely correlated response, exactly as predicted by the byproduct models of speciation (Coyne and Orr 2004). Such byproduct models of speciation predict that sexual isolation will arise as a result of either divergent natural selection (Rice and Hostert 1993) or divergent sexual selection (Svensson et al. 2006), both which may play a role in odonate divergence (Svensson and Friberg 
2007; Svensson et al. 2006). Another possibility may of course be that females are rejecting immigrant males because of indirect fitness costs, for example if offspring from such interpopulation matings have lower survival. However, we consider this possibility unlikely given the fairly pronounced gene flow between these populations (Svensson et al. 2004), and indirect fitness costs and benefits are also considered to be a relatively weak force in the evolution of mate preferences (Kirkpatrick and Barton 1997; Møller and Alatalo 1999; Arnqvist and Kirkpatrick 2005; Orteiza et al. 2005). The reason why premating isolation between the populations on the female side has not more efficiently reduced gene flow between the same populations could be due to male coercive mating behaviour (see above). If immigrant males are able to overcome discriminating local females by obtaining enforced copulations, such male mating behaviour would constrain population divergence by increasing gene flow in spite of emergent sexual isolation among females (see Parker and Partridge 1998).

\subsection{Conclusions and suggestions for future research}

The possibility that males, rather than females, are primarily responsible for hybridization, opens up new perspectives in future studies of hybridization and reproductive character displacement. For example, almost all studies on reinforcement and reproductive character displacement assume intrinsically that females are performing active mate choice and thus are responsible for hybridization. However, if males are driving the hybridization, it may lead to unexpected patterns. For example, there may be character displacement in secondary sexual characters of the males, but it may be caused by factors other than reinforcement of female mate preferences.

One alternative mechanism for reinforcement and patterns of reproductive character displacement is interference of the mate-recognition signals of the two species. For example, a female may have problems to distinguishing signals of her own species, increasing the costs of mate searching. This may cause similar selection on female mate preference and male sexual characters as does avoidance of maladaptive hybridization (see Noor 1999; Coyne and Orr 2004; Mullen and Andrés 2007). We suggest that interspecific aggression originating from mistaken species recognition may form an unrecognized form of interspecific interference, which may explain reinforcement of premating isolation (see also Mullen and Andrés 2007). In contrast to increasing the costs for females, mistaken species recognition between males may cause selection on males for better species recognition or divergence in their sexual characters. If male sexual characters and female mate preference are genetically correlated (Lande 1981), interspecific aggression may drive population divergence in male traits, cause a correlated response in female preferences and, as a result, produce a pattern similar to the one predicted by classical reinforcement theory (see Alatalo et al. 1994; Tynkkynen et al. 2004, 2005, 2006).

The melanized wings in Calopteryx are unique in their multifarious and pleiotropic effects on suites of adaptive functions such as their links to male immunological condition (Rantala et al. 2000; SivaJothy 2000), their effect on predation risk (Svensson and Friberg 2007), their importance in male-male interspecific interactions (Tynkkynen 2004, 2005, 2006), and their role in female choice and intraspecific sexual selection (Siva-Jothy 1999; Svensson et al. 2004). In addition to all these documented links to adaptive functions, wing pigmentation also functions as a sexual isolation mechanism between species (Svensson et al. 2007). The adaptive and multiple functions of melanized wings in combination with their role in mediating sexual isolation make these an excellent illustration of so-called 'magig-trait' models in speciation research (Gavrilets 2004). Future work in the genus Calopteryx should aim to clarify whether and how these wing pigmentations have influenced speciation rates in a broader phylogenetic context and the relative importance of natural and sexual selection in speciation processes in this and other odonate groups (Svensson et al. 2006). The relative simplicity by which these wing pigmentations can be measured and experimentally manipulated in natural populations should make Calopteryx damselflies excellent model organisms in future speciation research. 


\section{References}

Adams, D.C. (2004) Character displacement via aggressive interference in Appalachian salamanders. Ecology 85, 2664-2670.

Alatalo, R.V., Gustafsson, L., and Lundberg, A. (1994) Male coloration and species recognition in sympatric flycatchers. Proceedings of the Royal Society of London Series B 256, 113-118.

Arnqvist, G. and Kirkpatrick, M. (2005) The evolution of infidelity in socially monogamous passerines: the strength of direct and indirect selection on extrapair copulation behavior in females. American Naturalist 165, S26-S37.

Asahina, S. (1974) Interspecific hybrids among the Odonata. Japanese Journal of Zoology 17, 67-75.

Bick, G.H. and Bick, J.C. (1981) Heterospecific pairing among Odonata. Odonatologica 10, 259-270.

Butlin, R. (1987) Speciation by reinforcement. Trends in Ecology and Evolution 2, 8-13.

Chapman, T., Miyatake, T., Smith, H.K., and Partridge, L. (1998) Interactions of mating, egg production and death rates in females of the Mediterranean fruit fly, Ceratitis capitata. Proceedings of the Royal Society of London Series B 265, 1879-1894.

Corbet, P.S. (1999) Dragonflies: Behaviour and Ecology of Odonata. Harley Books, Essex.

Cordero, A. (1999) Forced copulations and female contact guarding at a high male density in a calopterygid damselfly. Journal of Insect Behavior 12, 27-37.

Cordero, A. and Andrés, J.A. (2002) Male coercion and convenience polyandry in a calopterygid damselfly. Journal of Insect Science 2, 14.

Córdoba-Aguilar, A. (2002) Wing pigmentation in territorial male damselflies, Calopteryx haemorrhoidalis: a possible relation to sexual selection. Animal Behaviour 63, 759-766.

Córdoba-Aguilar, A. (2006) Sperm ejection as a possible cryptic female choice mechanism in odonates (Insecta). Physiological Entomology 31, 146-153.

Coyne, J.A. and Orr, H.A. (1989) Patterns of speciation in Drosophila. Evolution 43: 362-381.

Coyne, J.A. and Orr, H.A. (2004) Speciation. Sinauer Associates, Sunderland, MA.

Dieckmann, U. and Doebeli, M. (1999) On the origin of species by sympatric speciation. Nature 400, 354-357.

Dobzhansky, T. (1951) Genetics and the Origin of Species, 3rd edn. Columbia University Press, New York.

Eccard, J.A. and Ylönen, H. (2002) Direct interference or indirect exploitation? An experimental study of fitness costs of interspecific competition in voles. Oikos 99, $580-590$.
Endler, J.A. (1977) Geographic Variation, Speciation and Clines. Princeton University Press, Princeton, NJ.

Felsenstein, J. (1981) Skepticism towards Santa Rosalia, or why are there so few kinds of animals? Evolution $35,124-138$.

Fincke, O.M. (1997) Conflict resolution in the Odonata: implications for understanding female mating patterns and female choice. Biological Journal of the Linnean Society 60, 201-220.

Fincke, O.M., Waage, J.R., and Koenig, W. (1997) Natural and sexual selection components of odonate mating patterns. In Choe, J.C. and Crespi, B. (eds), The Evolution of Mating Systems in Insects and Arachnids. Cambridge University Press, Cambridge.

Gavrilets, S. (2004) Fitness Landscapes and the Origin of Species. Princeton University Press, Princeton, NJ.

Genner, M.J., Turner, G.F., and Hawkins, S.J. (1999) Resource control by territorial male cichlid fish in Lake Malawi. Journal of Animal Ecology 68, 522-529.

Grant, P.R. and Grant, B.R. (1992) Hybridization of bird species. Science 256, 193-197.

Hendry, A.P. (2001) Adaptive divergence and the evolution of reproductive isolation in the wild: an empirical demonstration using introduced sockeye salmon. Genetica 112, 515-534.

Hendry, A.P., Wenburg, J.K., Bentzen, P., Volk, E.C., and Quinn, T.P. (2000) Rapid evolution of reproductive isolation in the wild: EVIDENCE from introduced salmon. Science 290, 516-518.

Hendry, A.P., Taylor, E.B., and McPhail, J.D. (2002) Adaptive divergence and the balance between selection and gene flow: lake and stream stickleback in the misty system. Evolution 56, 1199-1216.

Higgie, M., Chenoweth, S., and Blows, M.W. (2000) Natural selection and the reinforcement of mate recognition. Science 290, 519-521.

Howard, D.J. (1993) Reinforcement: origin, dynamics and fate of an evolutionary hypothesis. In Harrison, R.G. (ed.), Hybrid Zones and the Evolutionary Process, pp. 46-69. Oxford University Press, Oxford.

Kirkpatrick, M. and Barton, N.H. (1997) The strength of indirect selection on female mating preferences. Proceedings of the National Academy of Sciences USA 94, 1282-1286.

Kotiaho, J.S. (2001) Costs of sexual traits: a mismatch between theoretical considerations and empirical evidence. Biological Reviews 76, 365-376.

Kotiaho, J.S., Alatalo, R.V., Mappes, J., Nielsen, M.G., Parri, S., and Rivero, A. (1998) Energetic costs of size and sexual signalling in a wolf spider. Proceedings of the Royal Society of London Series B 265, 2203-2210. 
Lamont, B.B., He, T., Enright, N.J., Krauss, S.L., and Miller, B.P. (2003) Anthropogenic disturbance promotes hybridization between Banksia species by altering their biology. Journal of Evolutionary Biology 16, 551-557.

Lande, R. (1981) Models of speciation by sexual selection on polygenic traits. Proceedings of the National Academy of Sciences USA 78, 3721-3725.

Levin, D.A. (2004) The congener as an agent of extermination and rescue of rare species. In Ferriere, R., Dieckmann, U., and Couvet, D. (eds), Evolutionary Conservation Biology, pp. 344-355. Cambridge University Press, Cambridge.

Liou, L.W. and Price, T.D. (1994) Speciation by reinforcement of prezygotic isolation. Evolution 48, 1451-1459.

Mallet, J. (2005) Hybridization as an invasion of the genome. Trends in Ecology and Evolution 20, 229-237.

Martin, P.R. and Martin, T.E. (2001) Ecological and fitness consequences of species coexistence: a removal experiment with wood warblers. Ecology 82, 189-206.

McPeek, M.A. and Brown, J.M. (2000) Building a regional species pool: diversification of the Enallagma damselflies in Eastern North America. Ecology 421, 904-920.

Melville, J. (2002) Competition and character displacement in two species of scincid lizards. Ecology Letters 5, 386-393.

Misof, B., Anderson, C.L., and Hadrys, H. (2000) A phylogeny of the damselfly genus Calopteryx (Odonata) using mitochondrial $16 \mathrm{~S}$ rDNA markers. Molecular Phylogenetics and Evolution 15, 5-14.

Møller, A.P. and Alatalo, R. (1999) Good-genes effects in sexual selection. Proceedings of the Royal Society of London Series B 266, 85-91.

Monetti, L., Sánchez-Guillén, R.A., and Cordero Rivera, C. (2002) Hybridization between Ischnura graellsii (Vabder Linder) and I. elegans (Rambur) (Odonata: Coenagrionidae): are they different species? Biological Journal of the Linnean Society 76, 225-235.

Mullen, S.P. and Andrés, J.A. (2007) Rapid evolution of sexual signals in sympatric Calopteryx damselflies: reinforcement or 'noisy-neighbour' ecological character displacement? Journal of Evolutionary Biology 20, 1637-1648.

Murray, Jr, B.G. (1981) The origins of adaptive interspecific territorialism. Biological Reviews 56, 1-22.

Nishikawa, K.C. (1987) Interspecific aggressive behaviour in salamanders: species-specific interference or misidentification? Animal Behaviour 35, 263-270.

Nomakuchi, S. and Higashi, K. (1996) Competitive habitat utilization in the damselfly, Mnais nawai (Zygoptera: Calopterygidae) coexisting with a related species, Mnais pruinosa. Researches on Population Ecology 38, 41-50.
Noor, M.A.F. (1999) Reinforcement and other consequences of sympatry. Heredity 83, 503-508.

Nosil, P. (2004) Reproductive isolation caused by visual predation on migrants between divergent environments. Proceedings of the Royal Society of London Series B 271, 1521-1528.

Nosil, P., Crespi, B.J., and Sandoval, C.P. (2002) Host-plant adaptation drives the parallel evolution of reproductive isolation. Nature 417, 440-443.

Nosil, P., Crespi, B.J., and Sandoval, C.P. (2003) Reproductive isolation driven by the combined effects of ecological adaptation and reinforcement. Proceedings of the Royal Society of London Series B 270, 1911-1918.

Nuechterlein, G.L. and Buitron, D. (1998) Interspecific mate choice by late-courting male western grebes. Behavioral Ecology 9, 313-321.

Oppenheimer, S.D. and Waage, J.K. (1987) Handpairing: a new technique for obtaining copulations within and between Calopteryx species (Zygoptera: Calopterygidae). Odonatologica 16, 291-296.

Orteiza, N., Linder, J.E., and Rice, W.R. (2005) Sexy sons from re-mating do not recoup the direct costs of harmful male interactions in the Drosophila melanogaster laboratory model system. Journal of Evolutionary Biology 18, 1315-1323.

Parker, G.A. (1983) Mate quality and mating decisions. In: Bateson P, ed. Mate Choice, pp. 141-164. Cambridge University Press, Cambridge.

Parker, G.A. and Partridge, L. (1998) Sexual conflict and speciation. Philosophical transactions of the Royal Society of London, Series B. 353, 261-274.

Randler, C. 2002. Avian hybridization, mixed pairing and female choice. Animal Behaviour 63, 103-109.

Rantala, M.J., Koskimäki, J., Taskinen, J., Tynkkynen, K., and Suhonen, J. (2000) Immunocompetence, developmental stability and wingspot size in the damselfly Calopteryx splendens L. Proceedings of the Royal Society of London Series B 267, 2453-2457.

Rhymer, J.M. and Simberloff, D. (1996) Extinction by hybridization and introgression. Annual Review of Ecology and Systematics 27, 83-109.

Rice, W.R. and Hostert, E. (1993) Laboratory experiments on speciation: what have we learned in 40 years? Evolution 47, 1637-1653.

Rundle, H.D. and Schluter, D. (1998) Reinforcement of stickleback mate preferences: sympatry breeds contempt. Evolution 52, 200-208.

Sætre, G.-P., Moum, T., Bures, S., Král, M., Adamjan, M., and Moreno, J. (1997a) A sexually selected character displacement in flycatchers reinforces premating isolation. Nature 387, 589-592. 
Sætre, G.-P., Král, M., and Bures, S. (1997b) Differential species recognition abilities of males and females in a flycatcher hybrid zone. Journal of Avian Biology 28, 259-263.

Sætre, G.-P., Král, M., Bureš, S., and Ims, R.A. (1999) Dynamics of a clinal hybrid zone and a comparison with island hybrid zones of flycatchers (Ficedula hypoleuca and F. albicollis). Journal of Zoology 247, 53-64.

Sánchez-Guillén, R.A., Van Gossum, H., and Cordero Rivera, A. (2005) Hybridization and the inheritance of female colour polymorphism in two ischnurid damselflies (Odonata: Coenagrionidae). Biological Journal of the Linnean Society 85, 471-481.

Seehausen, O. and van Alphen, J.J.M. (1998) The effect of male coloration on female mate choice in closely related Lake Victoria cichlids (Haplochromis nyererei complex). Behavioral Ecology and Sociobiology 42, 1-8.

Seehausen, O., van Alphen, J.J.M., and Witte, F. (1997a) Cichlid fish diversity threatened by eutrophication that curbs sexual selection. Science 277, 1808-1811.

Seehausen, O., Witte, F., Katunzi, E.F., Smits, J. and Bouton, N. (1997b) Patterns of the remnant cichlid fauna in southern Lake Victoria. Conservation Biology 11, 890-904.

Servedio, M.R. (2001) Beyond reinforcement: the evolution of premating isolation by direct selection on preferences and postmating, prezygotic incompatibilities. Evolution 55, 1909-1920.

Siva-Jothy, M.T. (1999) Male wing pigmentation may affect reproductive success via female choice in a calopterygid damselfly (Zygoptera). Behaviour 136, 1365-1377.

Siva-Jothy, M.T. (2000) A mechanistic link between parasite resistance and expression of a sexually selected trait in a damselfly. Proceedings of the Royal Society of London Series B 267, 2523-2527.

Smith, T.B., Wayne, R.K., Girman, D.J., and Bruford, M. (1997) A role for ecotones in generating rainforest biodiversity. Science 276, 1855-1857.

Svensson, E.I. and Friberg, M. (2007) Selective predation on wing morphology in sympatric damselflies. American Naturalist 170, 101-112.

Svensson, E.I., Kristoffersen, L., Oskarsson, K., and Bensch, S. (2004) Molecular population divergence and sexual selection on morphology in the banded demoiselle (Calopteryx splendens). Heredity 93, 423-433.

Svensson, E.I., Eroukhmanoff, F., and Friberg, M. (2006) Effects of natural and sexual selection on adaptive population divergence and premating isolation in a damselfly. Evolution 60, 1242-1253.
Svensson, E.I., Karlsson, K., Friberg, M., and Eroukhmanoff, F. (2007) Gender differences in species recognition and the evolution of asymmetric sexual isolation. Current Biology 17, 1943-1947.

Taylor, E.B., Boughman, J.W., Groenenboom, M., Sniatynski, M., Schluter, D., and Gow, L. (2006) Speciation in reverse: morphological and genetic evidence of the collapse of a three-spined stickleback (Gasterosteus aculeatus) species pair. Molecular Ecology 15, 343-355.

Tynkkynen, K., Rantala, M.J., and Suhonen, J. (2004): Interspecific aggression and character displacement in the damselfly Calopteryx splendens. Journal of Evolutionary Biology 17, 759-767.

Tynkkynen, K., Kotiaho, J.S., Luojumäki, M., and Suhonen, J. (2005) Interspecific aggression causes negative selection on sexual characters. Evolution 59, 1838-1843.

Tynkkynen, K., Kotiaho, J.S., Luojumäki, M., and Suhonen, J. (2006) Interspecific territoriality in Calopteryx damselflies: the role of secondary sexual characters. Animal Behaviour 71, 299-306.

Tynkkynen, K., Grapputo, A., Kotiaho, J.S., Rantala, M.J., Väänänen, S., and Suhonen, J. (2008) Hybridization in Calopteryx damselflies: the role of males. Animal Behaviour, 75, 1431-1439.

Veen, T., Borge, T., Griffith, S.C., Sætre, G.-P., Bures, S., Gustafsson, L., and Sheldon, B.C. (2001) Hybridization and adaptive mate choice in flycatchers. Nature 411, 45-50.

Waage, J.K. (1975) Reproductive isolation and the potential for character displacement in the damselflies, Calopteryx maculata and C. aequabilis (Odonata: Calopterygidae). Systematic Zoology 24, 24-36.

Waage, J.K. (1979) Reproductive character displacement in Calopteryx (Odonata: Calopterygidae). Evolution 33, 104-116.

Weekers, P.H.H., De Jonckheere, J.F., and Dumont, H.J. (2001) Phylogenetic relationships inferred from ribosomal ITS sequences and biogeographic patterns in representatives of the genus Calopteryx (Insecta: Odonata) of the west Mediterranean and Adjacent west European zone. Molecular Phylogenetics and Evolution 20, 89-99.

Wirtz, P. (1999) Mother species-father species: unidirectional hybridization in animals with female choice. Animal Behaviour 58, 1-12.

Zuk, M. and Kolluru, G.R. (1998) Exploitation of sexual signals by predators and parasitoids. Quarterly Review of Biology 73, 415-438. 